\title{
Massive Spinal Subdural Hematoma and Subarachnoid Hemorrhage in a Patient Receiving Oral Anticoagulant Therapy
}

\author{
Ahmet Baydın', Latif Duran', Mustafa Bilgiç', Ramazan Amanvermez², Cengiz Çokluk, Meltem Ince \\ 'Department of Emergency Medicine, Ondokuz Mayıs University School of Medicine, Samsun, Turkey \\ 2Department of Biochemistry, Ondokuz Mayıs University School of Medicine, Samsun, Turkey \\ 3Department of Neurosurgery, Ondokuz Mayıs University School of Medicine, Samsun, Turkey
}

\section{ABSTRACT}

Introduction: We present a rare clinical condition of concomitant spinal subdural hematoma and cranial subarachnoid hemorrhage $(\mathrm{SAH})$ related to oral anticoagulant therapy.

Case Report: In this report, we present the case of a 78 -year- old female who was brought by an ambulance to the emergency department with sudden onset neurological deficit, which was eventually diagnosed as a simultaneous spinal subdural hematoma and SAH.

Conclusion: The coagulation profile of patients should be screened in the context of anticoagulant therapy in appropriate or short time periods; an early clinical intervention will result in a greater likelihood of the patient's recovery.

Keywords: Emergency service, subarachnoid hemorrhage, spinal subdural hematoma, anticoagulant therapy

Received: 10.06.2015 Accepted:07.10.2015

\section{Introduction}

Hemorrhage is a common complication in patients undergoing anticoagulant therapy when it is halted to screen a patient's coagulation system; also, the frequency of bleeding resulting from anticoagulant therapy increases with long-term usage (1). In relation to this issue, bleeding may occur in different anatomic regions, such as intra-cranial, intra-spinal, intra-thoracic, intra-abdominal, intra-joint, epistaxis, urinary, and gastrointestinal regions (1-4). Life-threatening intra-cranial and spinal hemorrhages are the most serious complications of oral anticoagulant therapy. A couple of articles in the literature have reported that a spinal hemorrhage that might have evolved secondary to anticoagulant therapy, may be seen in epidural, subdural, subarachnoid, and intra-spinal cases in the absence of abnormalities of coagulation, blood dyscrasias, lumber puncture or trauma, neoplasm, and arterio-venous malformation (5-7). Although intra-cranial hemorrhage along with spinal epidural hematoma can occur often, spinal subdural hematoma rarely occurs (2-6). The occurrence of spinal subdural hematoma along with intra-cranial subarachnoid hemorrhage (SAH) is extremely rare. Herein, we discuss the case of an elderly female who had concomitant spinal subdural hematoma and cranial SAH associated with warfarin therapy.

\section{Case Report}

A 78-year-old female patient was admitted to the emergency department (ED) with complaints of weakness in her legs, a walking deficit, and lumbar pain, which she experienced for 5 days prior to admission. She had a history of atrial fibrillation 3 years previously and had been taking a pill of $7.5 \mathrm{mg}$ of warfarin sodium daily for the last 15 months because of her atrial fibrillation. Also, atrial fibrillation was detected in her 12-lead electrocardiogram on admission. In addition, she was taking amlodipine (Norvasc 5 mg, Pfizer, Dublin, Ireland) daily and insulin for her hypertension and diabetes mellitus, respectively. A physical and clinical examination was performed and the findings were as follows: temperature: $37.2^{\circ} \mathrm{C}$, pulse rate: $118 \mathrm{beat} / \mathrm{min}$, blood pressure: 130/80 $\mathrm{mmHg}$, respiratory rate: 20 breath/min, and oxygen saturation: $98 \%$ on room air. She was alert and completely

\section{Address for Correspondence:}

Ahmet Baydın, Department of Emergency Medicine, Ondokuz Mayıs University School of Medicine, Samsun, Turkey

E-mail: abaydin@omu.edu.tr

oCopyright 2016 by Emergency Physicians Association of Turkey - Available online at www.jemcr.org 
Table 1. Laboratory findings of the patient on admission

\begin{tabular}{|c|c|c|}
\hline Lab. Tests & Value & Normal Range \\
\hline White blood cells & $15.4 \times 103 / \mu \mathrm{L}$ & $4.3-10.3 \times 103 / \mu \mathrm{L}$ \\
\hline Hemoglobin & $13.7 \mathrm{~g} / \mathrm{dL}$ & $13.3-17.2 \mathrm{~g} / \mathrm{dL}$ \\
\hline Hematocrit & $41.8 \%$ & $39.3 \%-50.33 \%$ \\
\hline Platelets & $259 \times 103 / \mu \mathrm{L}$ & $172-44 \times 103 / \mu \mathrm{L}$ \\
\hline Glucose & $588 \mathrm{mg} / \mathrm{dL}$ & $70-110 \mathrm{mg} / \mathrm{dL}$ \\
\hline $\mathrm{AST}^{*}$ & $48 \mathrm{U} / \mathrm{L}$ & 8-46 U/L \\
\hline $\mathrm{ALT}^{*}$ & $30 \mathrm{U} / \mathrm{L}$ & $7-46 \mathrm{U} / \mathrm{L}$ \\
\hline Creatine phosphokinase & $654 \mathrm{U} / \mathrm{L}$ & 35-195 U/L \\
\hline Total bilirubin & $1.5 \mathrm{mg} / \mathrm{dL}$ & $0.1-1.5 \mathrm{mg} / \mathrm{dL}$ \\
\hline Direct bilirubin & $0.1 \mathrm{mg} / \mathrm{dL}$ & $0.0-0.4 \mathrm{mg} / \mathrm{dL}$ \\
\hline Blood urea nitrogen & $36 \mathrm{mg} / \mathrm{dL}$ & $8-25 \mathrm{mg} / \mathrm{dL}$ \\
\hline Creatinine & $1.59 \mathrm{mg} / \mathrm{dL}$ & $0.4-1.4 \mathrm{mg} / \mathrm{dL}$ \\
\hline Sodium & $133 \mathrm{mEq} / \mathrm{L}$ & $135-145 \mathrm{mEq} / \mathrm{L}$ \\
\hline Potassium & $3.9 \mathrm{mEq} / \mathrm{L}$ & $3.5-5.1 \mathrm{mEq} / \mathrm{L}$ \\
\hline Chloride & $91 \mathrm{mEq} / \mathrm{L}$ & 99-110 mEq/L \\
\hline Calcium & $10.2 \mathrm{mg} / \mathrm{dL}$ & $8.1-10.7 \mathrm{mg} / \mathrm{dL}$ \\
\hline Prothrombin time & $>120 \mathrm{~s}$ & $10-14 s$ \\
\hline $\mathrm{aPTT}^{*}$ & $<18 s$ & $22-35 s$ \\
\hline $\mathrm{INR}^{*}$ & immeasurably high & $0.85-1.15$ \\
\hline
\end{tabular}

AST $^{*}$ : aspartate transaminase, ALT* $^{*}$ alanine transaminase, aPTT*: activated

partial thromboplastin time, INR*: international normalized ratio

oriented and was able to answer questions appropriately. Her pupils were equal, round, and reactive to light, with intact extra ocular movements. Her heart beats were irregular without any murmur, rub, or gallop, and her rectal tone was normal. Examination of her motor strength in both lower extremities revealed a power of 2-5. Her deep tendon reflexes were also absent on both lower extremities. Her prothrombin time (PT) was prolonged tolerably and her international normalized ratio (INR) level was immeasurably high. The patient's other initial laboratory findings are shown in Table 1. In addition to these findings, because of a suspected spinal hemorrhage, magnetic resonance imaging (MRI) of the thoraco-lumbar spine was performed. The MRI scan of this region showed evidence of a massive subdural hemorrhagic collection (hematoma). The subdural hematoma is shown in Figure A (T2-weighted sagittal image) and Figure B (T2-weighted axial image) at the thoracic and lumbar levels with a compression of the spinal cord. Additionally, the patient suffered a sudden onset of headache on admission day. Then, a cranial computed tomography (CT) scan of the patient was performed, and the CT image revealed a cranial SAH, as shown in Figure C. However, her chest X-ray image was normal. After clinical and radiological evaluation of the patient, an acute spinal subdural and intra-cranial SAH was diagnosed; subsequently, fresh frozen plasma (5 units) and vitamin K were medically administered to her, with an aim to limit ongoing bleeding and improve her outcome. Following this treatment, her INR level decreased at the rate of 2.1 after $6 \mathrm{~h}$. According to her MRI and CT findings, neurosurgical options for a

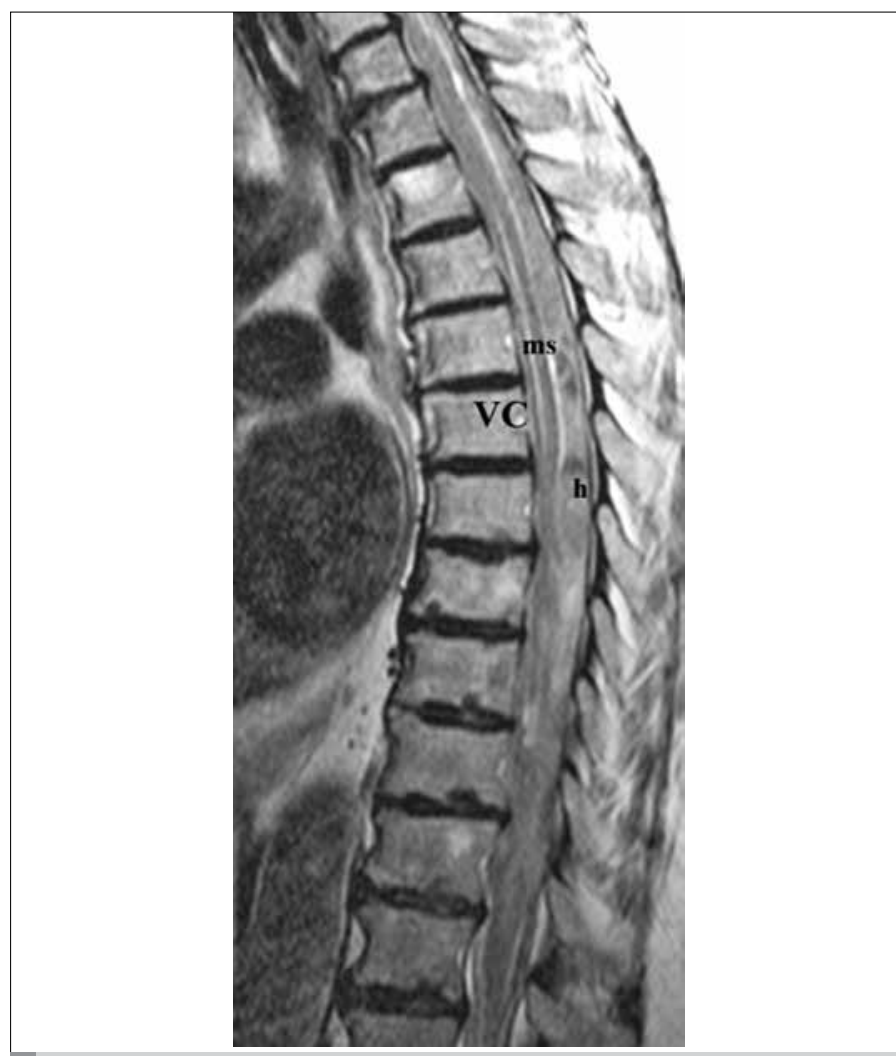

Figure A. T2-weighted axial image showing the location of the spinal subdural hematoma (VC: Vertebral Corpus, ms: medulla spinalis, h: hematoma, I: lamina)

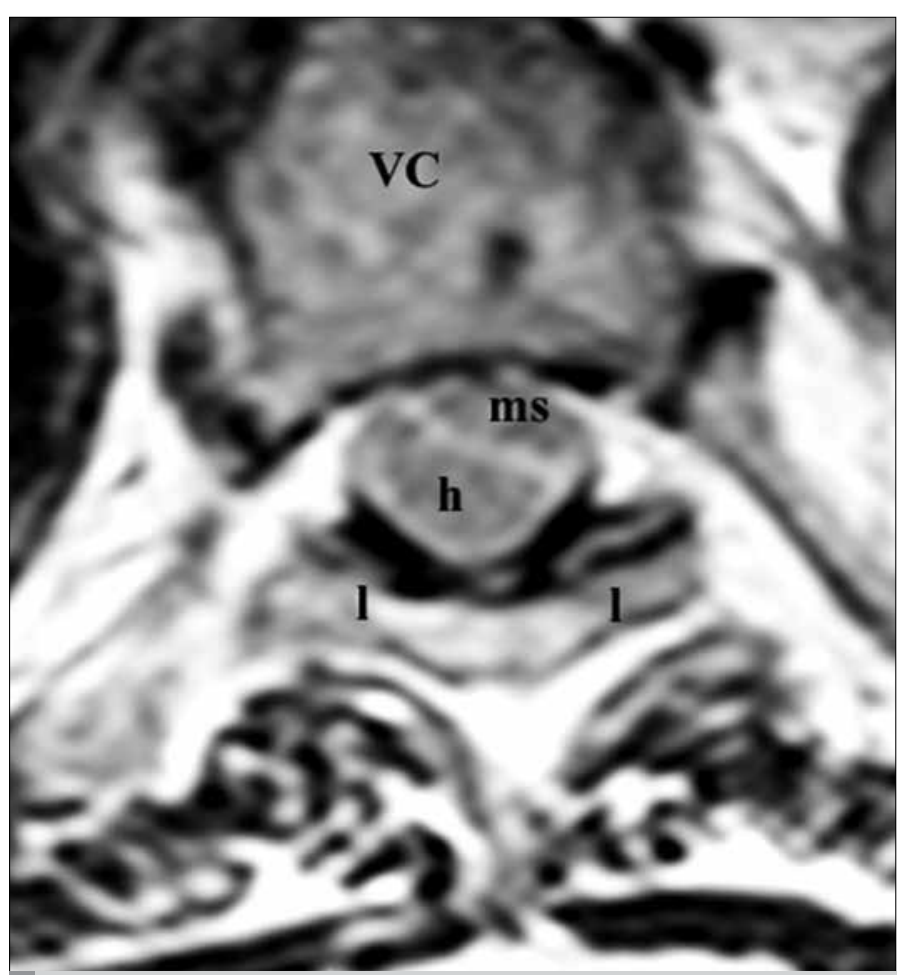

Figure B. T2-weighted sagittal image of the thoracic region showing the location and extent of the subdural hematoma (VC: vertebral corpus, ms: medulla spinalis, h: hematoma). 


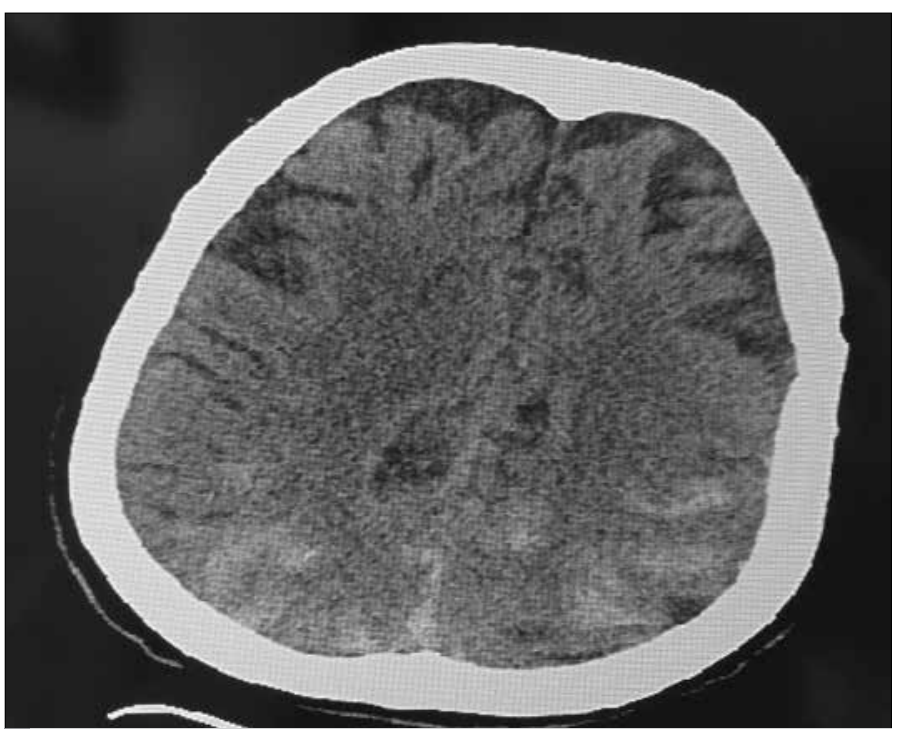

Figure C. Computerized head scan showing the subarachnoid hemorrhage located in the parieto-occipital region.

medical remedy were sought. The neurosurgeon did not consider an operation for the patient because the time of the hemorrhage onset and clinical nature of the patient's symptoms. Therefore, the patient was hospitalized in the neurosurgery ward. The patient was managed with a conservative treatment in the neurosurgical unit; however, the patient's neurological findings did not improve. Unfortunately, the patient died on the 21 st day after admission to the ED. The patient's informed consent was obtained before preparation of this report.

\section{Discussion}

Spinal hematomas may occur as a complication of hemorrhagic diathesis, thrombocytopenia, invasive spinal surgery, traumas, spinal anesthesia, thrombotic disorders, thrombocytopenia, or lumbar puncture; hemorrhage might also be developed in patients after receiving warfarin therapy only (6-8). Warfarin may be used to preserve anticoagulation for prophylaxis or for the treatment of thrombosis, which has been reported in patients with atrial fibrillation, valvular heart disease, mechanical heart valves, deep vein thrombosis, pulmonary emboli, and acute ischemic stroke (9). However, there is a powerful relationship between the intensity of anticoagulant treatment and the risk of bleeding. The intensity of the anticoagulant effect is most likely to be an important risk factor for intra-cranial hemorrhage, independent of the indication for therapy, with the risk increasing dramatically with an INR of $>4.0-5.0$. The risk of intracerebral hemorrhage, the most feared and the most deadly complication of oral anticoagulant therapy, e.g., with warfarin sodium (Coumadin ${ }^{\oplus}$, Zentiva, İstanbul, Turkey), is doubled with the increase of approximately each unit in the INR, as reported by Goldstein and Greenberg (10). Therefore, patients receiving anticoagulant therapy should be monitored in clinics for therapeutic INR optimization (targeted INR<2.0) in consideration of the bleeding risks. At the same time, the bleeding risk for intra-cranial hemorrhage may be high among older patients, in particular those aged $>75$ years, when the INR is above therapeutic levels (11).
Some comorbid diseases have been associated with bleeding during warfarin therapy; these diseases include treated hypertension, cerebrovascular disease, ischemic stroke, malignancy, heart failure, and renal insufficiency (9-11). In our reported case, even after the clinical examination on the initial presentation, our patient continued to receive a drug for hypertension and diabetes mellitus, and furthermore the patient was taking warfarin therapy because of atrial fibrillation. Also, she was an older patient and she also had an abnormal coagulation profile (highly elevated PT and immeasurably high INR). On the basis of the patient's characteristics, the intensity of the anticoagulant effect and comorbid diseases, it seems most likely that an intraspinal hematoma and intra-cranial hemorrhage in a patient on anticoagulant therapy will occur. In addition to this, bleeding might result from other body parts in the context of coagulation abnormalities as well. Decompression of the spinal cord via neurosurgical evacuation of the hematoma is one option in the current management of these patients with spinal cord compression associated with neurological deficits. But on the other hand, the general medical condition of the patient and the worsening of the cranial pathology should be considered when making a decision about surgical treatment.

In conclusion, spinal subdural hematoma and intra-cranial SAH are known to be neurological emergencies. A patient's coagulation profile should be screened in the context of anticoagulant therapy in appropriate or short time periods, as an early clinical intervention will result in a greater likelihood of the patient's recovery.

Informed Consent: Written informed consent was obtained from patient who participated in this case.

Peer-review: Externally peer-reviewed.

Author contributions: Concept - A.B.; Design - A.B., M.B.; Supervision - A.B.; Resource - L.D., M.I.; Analysis and/or Interpretation - A.B., C.Ç.; Literature Search - L.D., M.I.; Writing - A.B., C.Ç., R.A.; Critical Reviews - C.Ç., R.A.

Conflict of Interest: The authors declared no conflict of interest.

Financial Disclosure: The authors declared that this study has received no financial support.

\section{References}

1. Sagar J, Kumar V, Shah DK, Bhatnagar A. Spontaneous intra-peritoneal bleeding secondary to warfarin, presenting as an acute appendicitis: a case report and review of literature. BMC Blood Disord 2006; 6: 7. [CrossRef]

2. Kishen T, Etherington G, Diwan A. Cranial subdural haematoma with concomitant spinal epidural and spinal subarachnoid haematomas: a case report. J Orthop Surg 2009; 17: 358-60.

3. Doğan NÖ, Pamukçu Günaydın G, Tekin M, Çevik Y. Nontraumatic Massive Spontaneous Hemothorax with Concomitant Warfarin Use. Case Rep Emerg Med 2013; 1-3. [CrossRef]

4. Steiner T, Rosand J, Diringer M. Intracerebral hemorrhage associated with oral anticoagulant therapy: current practices and unresolved questions. Stroke 2006; 37: 256-62. [CrossRef] 
5. Cincu R, de Asis Lorente F, Rivero D, Eiras J, Ara JR. Spontaneus subdural hematoma of the thoracolumbar region with massive recurrent bleed. Indian J Orthop 2009; 43: 412-5. [CrossRef]

6. Mete A, Erkutlu I, Akcalı A, Mete A. Simultaneous cranial subarachnoid hemorrhage and spinal subdural hematoma. Turk Neurosurg 2012; 22: 349-52.

7. Kakitsubata Y, Theodorou SJ, Theodorou DJ, Miyata Y, Ito Y, Yuki Y, et al. Spontaneous spinal subarachnoid hemorrhage associated with subdural hematoma at different spinal levels. Emerg Radiol 2010; 17: 69-72. [CrossRef]

8. Badge R, Chan D. Spinal subdural haematoma in association with anticoagulant therapy, an unusual presentation: a case report and review of literature. Cases J 2009; 2: 151. [CrossRef]
9. Levine MN, Raskob G, Beyth RJ, Kearon C, Schulman S. Hemorrhagic complications of anticoagulant treatment: the Seventh ACCP Conference on Antithrombotic and Thrombolytic Therapy. Chest 2004; 126: 287S-310S. [CrossRef]

10. Goldstein JN, Greenberg SM. Should anticoagulation be resumed after intracerebral hemorrhage? Cleve Clin J Med 2010; 77: 791-9. [CrossRef]

11. Hylek EM, Evans-Molina C, Shea C, Henault LE, Regan S. Major Hemorrhage and Tolerability of Warfarin in the First Year of Therapy Among Elderly Patients With Atrial Fibrillation. Circulation 2007; 115: 2689-96. [CrossRef] 